\title{
Pure sensory stroke due to midbrain haemorrhage limited to the spinothalamic pathway
}

\author{
Ph AZOUVI,* A TOUGERON, ${ }^{*}$ C HUSSONOIS, ** E SCHOUMAN-CLAEYS, $\dagger$ \\ B BUSSEL, * J P HELD*
}

From the Service de Rééducation Neurologique, ${ }^{*}$ the Service de Radiologie, $\dagger$ Hopital Raymond Poincaré, Garches, and the Service de Médecine, Centre Hospitalier d'Auxerre, ${ }^{* *}$ France

SUMMARY A 62 year old man suddenly presented with a pure left sensory deficit involving only pain and temperature sensations. CT scan and MRI showed a small haemorrhage in the dorsolateral part of the right midbrain. This suggested a lesion limited to the right dorsal spinothalamic tract.

Pure sensory stroke (PSS) syndrome, first reported by Fisher in $1965,{ }^{1}$ is defined by the sudden occurrence of dysaesthesia and of a sensory deficit involving the face, arm and leg on one side of the body, without any other neurological sign or symptom. In the first pathological studies, ${ }^{12}$ this syndrome was due to a lacunar infarct of the sensory nucleus of the contralateral thalamus. Since then, several reports ${ }^{3-10}$ have shown that it can also be due to different lesion mechanisms, meaning either ischaemic or haemorrhagic, and to various lesion locations, including the thalamus, but also the superficial territory of the middle cerebral artery, the posterior part of the internal capsule, the midbrain and the pons. However, cases of PSS due to brainstem haematoma remain exceptional. We report a case of PSS due to a small haemorrhage in the dorsal midbrain which was most unusual because it involved only extralemniscal pathways.

\section{Case report}

On 15 March 1988, a previously healthy 62 year old man suddenly experienced on waking an unusual sensation in the left part of his body, without any pain or dysaesthesia. He was unable to feel heat in his left hand and left foot, which he pointed out spontaneously. There was no headache. He was referred to the hospital the same day. His temperature was $36.7^{\circ} \mathrm{C}$, blood pressure $150 / 90 \mathrm{~mm} \mathrm{Hg}$ and pulse $90 / \mathrm{min}$.

Correspondence to: $\mathrm{Dr} \mathrm{Ph}$ Azouvi, Service de Rééducation Neurologique, Hopital Raymond Poincaré, 92380, Garches, France.

Received 29 March 1989.

Accepted 19 June 1989
Neurological examination showed loss of temperature and pain sensations that involved the entire left side of his body, including the face, up to its midline. Touch, vibration and position sensations, graphaesthesia and stereognosia were strictly normal. He was alert and well oriented. Cranial nerves were normal and there was no pupil asymmetry. Motor and cerebellar functions were also normal and tendon jerks were symmetrical and plantar responses were flexor. Usual laboratory examinations, ECG and chest radiographs were normal.

An unenhanced CT, performed the next day (fig a), revealed a spontaneous round hyperdensity, of approximately $7 \mathrm{~mm}$ diameter, located in the right dorsal tegmentum of the midbrain, highly suggestive of a small haematoma. Cerebral angiography, on 28 March was normal. Magnetic resonance imaging (MRI) two days later showed on T1 WI a small hyperintense signal in the right mesencephalic tegmentum, just in front of the right anterior colliculus (figs b c).

Visual fields, ocular motility, optic fundi and visual acuity showed no abnormality. Visual and auditory brainstem evoked potentials were normal. Somatosensory evoked potentials, performed on 29 March, were normal after stimulation of median nerve, but after stimulation of the posterior tibial nerve, they showed a prolonged latency of the left P60 component.

The patient's neurological disorders progressively resolved within six weeks. Two months after the onset of the disease, both neurological examination and CT with and without contrast infusion were strictly normal.

\section{Discussion}

Lacunar syndromes due to intracerebral haemorrhage are now well recognised, since the development of CT." However, although PSS is one of the most frequent lacunar syndromes, ${ }^{12}$ Mori et al ${ }^{11}$ did not 

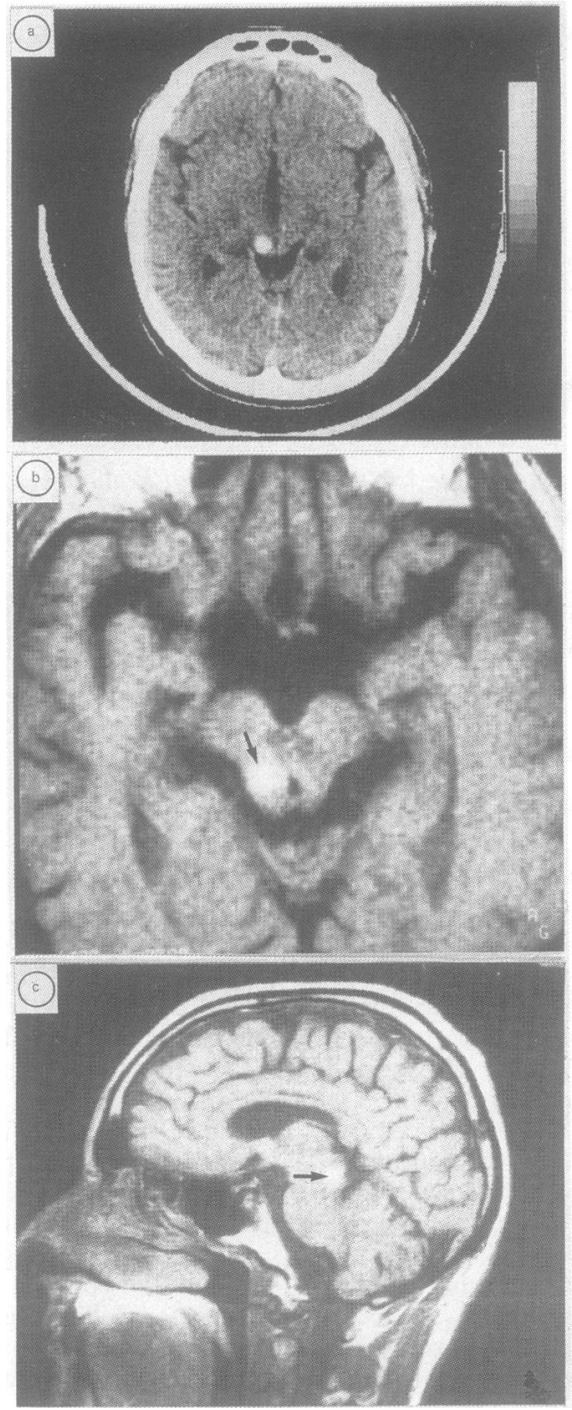

Fig (a) CT scan, (b) axial and (c) sagittal TIWI MRI showing a small haematoma (arrow) in right dorsolateral midbrain.

observe any in their 19 cases of haemorrhagic lacunar syndromes. Haemorrhagic PSS therefore seems to be exceptional. To date, seven cases have been reported in the literature: two with thalamic haematoma, ${ }^{40}$ three with pontine haemorrhage ${ }^{89}$ one with haematoma in the internal capsule ${ }^{3}$ and one with midbrain haemorrhage. ${ }^{5}$ In this last case, a 52 year old man suddenly experienced numbness and tingling in the right arm and leg, without any sensory deficit. He had no hypertensive history. CT revealed a small haemorrhage in the left dorsolateral midbrain.

In our patient, the sensory disorders were different. Subjective symptoms were very discrete, there was no dysaesthesia; there was a marked deficit of pain and temperature sensations, while touch, vibration and position sensations were essentially normal. CT and MRI showed a haematoma in the mesencephalic tegmentum, in its dorsal and lateral areas, just in front of the superior colliculus. Both clinical and neuroradiological data suggested that the damage was restricted to the right dorsal spinothalamic tract, and did not involve the ipsilateral medial lemniscus, which is located more anteriorly.

To our knowledge, such a dissociation between lemniscal and extralemniscal sensations in a case of PSS has not been reported before. In two observations,${ }^{89}$ reverse dissociation was observed in cases of pontine haemorrhage: in these patients, touch or proprioceptive sensations were affected, but temperature and pain sensations were normal. The authors concluded that the damage was restricted to the medial lemniscus in the pons. Our case, together with these observations, shows that small haematoma located on the sensory pathways before they reach the thalamus, can produce partial PSS, involving either the central lemniscus, or the dorsal spinothalamic tract.

\section{References}

1 Fisher CM. Pure sensory stroke involving face, arm ar leg. Neurology 1965;15:76-80.

2 Fisher CM. Thalamic pure sensory stroke: a pathologi study. Neurology 1978;28:1141-4.

3 Groothuis DR, Duncan GW, Fisher CM. The huma thalamocortical sensory path in the internal capsut evidence from a small capsular hemorrhage causing $\vec{a} \vec{\omega}$ pure sensory stroke. Ann Neurol 1977;2:328-31.

4 Rosenberg NL, Koller R. Computerized tomography and pure sensory stroke. Neurology 1981;31:217-20.

5 Tuttle PV, Reinmuth OM. Midbrain hemorrhage producing pure sensory stroke. Arch Neurol 1984;41: $\frac{\bar{\partial}}{2}$ 794-5.

6 Derouesne C, Mas JL, Bolgert F, Castaigne P. Pure $\stackrel{\circ}{\overparen{Q}}$ sensory stroke caused by a small cortical infarct in the middle cerebral artery territory. Stroke 1984;15:660-2. 음

7 Derouesne C, Yelnik A, Castaigne P. Deficit sensitif isolé 3 par infarctus dans le territoire de l'artère choroidienne antérieure. Rev Neurol (Paris) 1985;141:311-4.

8 Graveleau $\mathrm{Ph}$, Decroix JP, Samson Y, Masson $\mathrm{M}, \stackrel{\overrightarrow{\widehat{S}}}{ }$ Cambier J. Déficit sensitif isolé d'un hémicorps par hématome du pont. Rev Neurol 1986;142: 788-90.

9 Araga S, Fukada M, Kagimoto H, Takahashi K. Pure sensory stroke due to pontine haemorrhage. J Neurol 1987;235:116-7.

10 Azouvi Ph, Pappata S, Baron JC, Bousser MG, Laplane D. Attaque sensitive pure par hématome thalamique. Rev Neurol 1988;144:212-4.

11 Mori E, Tabuchi M, Yamadori A. Lacunar syndrome due to intracerebral hemorrhage. Stroke 1985;16: Л 454-9.

12 Fisher CM. Lacunar strokes and infarcts: a review. Neurology 1982;32:871-6. 